\title{
Survey on examining the student's cognizance on usage of Cloud Computing in Higher Education
}

Mrs. Sowmya Jyothi

Asst. Professor, BCA Department, SDM College of Business Management, Mangalore, Karnataka, India

\section{Article Info}

Volume 7, Issue 2

Page Number: 348-354

\section{Publication Issue :}

March-April-2021

\section{Article History}

Accepted : 01 April 2021

Published : 15 April 2021

\begin{abstract}
Due to the advent of technology classroom teaching is adopting changes in the modern education system. Today, students have become more tech savvy as teaching and learning uses more advance technology day in, day out. The economic growth of any country is usually maintained and enhanced by education in terms of quality and level. Cloud computing is an exciting development in modern education system. Understanding the role of higher education institutions in Cloud Computing adoption is a necessary research area. Higher education institutions must consider opportunities afforded by cloud computing. The main purpose of this paper is to examine the student's awareness on usage of Cloud Computing in Education. This study emphasizes the need for the relevance of improvising education by creating awareness among the students of Mangalore city. These researches encourage higher education institutions to adopt cloud computing technology.
\end{abstract}

Keywords: Cloud Computing, Higher Education

\section{INTRODUCTION}

New technologies are being developed every day, which have become part of each other's life. People across the world are adopting new technologies to meet their needs in a cost-effective way. Today's technologies have advanced so much that they offer large amounts of data with a incredible speed, as well as with an massive storage capacity. Computer technology has become a requisite part of everyday life. Also, the need for cloud computing is becoming increasingly evident. [Youseff et al. (2008)] stated that cloud computing is not a completely new concept but a combination of new and already existing technology. As defined by U.S National
Institute of Standards and Technology (NIST 2011), Cloud computing is a shared pool of various computing resources like networks, servers, storage, applications and services that can be readily accessed through internet. Cloud computing is an important subject to study, especially its application in universities and its use by students. So, the purpose of this research is to identify the main factors that affect the use or non-use of cloud computing by students in Mangalore region. As the reliability for utilising cloud computing is on the internet for all the applications and data, cloud computing has certain limitations with more benefits. Cloud computing is advantageous due to the real time and online accessibility of the data and applications that aids in it 
overwhelming adoption in education and various other activities in a cost-effective manner and adaptability to new technologies. Potential of using cloud computing for the students relies due to the various factors like cost-effectiveness, user friendly, easy accessibility, can be applied in online teaching, work or entertainment, to implement group projects that also aids in creating, sharing and editing the documents and presentations, completion of tasks/assignments. Therefore, understanding the curiosity, awareness and the willing to adopt of cloud computing by the students is interesting and gets remarkable when more suitable environment is created for its implementation in the universities. Cloud computing is an evolving technology with its rapid use on laptops, Tablets and Smartphones as per the needs of the user with high storage of data and accessible applications, computing power and online services which are free as well as paid which has revolutionised the Information technology.

Various shared resources like servers, storage and applications as provided by Amazon IBM, Google's Application, Microsoft Azure are enabled through the network via Cloud computing technology for the formal and informal education which aids the students and teachers making more flexible, easy sharing and communication of learning resources and also creating personalised learning environment. This drives in curiosity among the student community and teachers to utilise the cloud computing in education when supported by the Government funds and the Institutional regulations for the adaptability of upcoming trends of the technology in education.

This article based on the data obtained from the survey and literature study intends to explore the about cloud computing as perceived by the students which favors their education, E-skills and also the need for creating awareness among the students and the management.

\section{Purpose of the study}

The purpose of this survey is to identify the importance of adopting cloud computing in higher education. To understand their willingness and intention to update the knowledge to adopt cloud computing technology. Secondly to analyze the major factors that prevents the adoption of Cloud Computing in education.

\section{SURVEY AND INTERVIEW}

\subsection{Data Collection}

The data collected for this research were from both primary and secondary sources. The primary source data were collected using questionnaires, while the secondary source data were gathered from academic Journals, publications, the Internet and literature based on cloud computing. The information gathered from secondary data was the building blocks with which the researcher was able to develop the paper topic and also determine the information necessary in obtaining the primary data for the research.

\subsubsection{Primary Data Collection}

\subsubsection{Questionnaires}

The questionnaire was designed using Google Form, an online survey application and distributed for students because this allowed for easy administration of questionnaires once they were designed. It also allowed for easier statistical analysis.

\subsubsection{Secondary Data}

The secondary data used for this research was obtained from academic journals from science direct, Emerald, Google scholar search engines, Research Gate, IEEEXplore digital library etc. Also, many useful publications from internet were used. The data from these resources were useful in developing the 
literature review, the research objectives and research plan.

\section{ANALYSIS ON DATA AND RESULT}

This section presents an account of the research findings gathered from both questionnaires and interviews tailored at determining the extent of cloud computing adoption by the students in education. The questionnaire was used to collect responses from the students. The questionnaire-based survey had a set of questions administered through a Google Form, consisting of multiple-choice; check-boxes based questions which included 12 questions. Overall, 92 respondents participated in the survey.

\subsection{Analysis of Questionnaire}

In order to know the extent of cloud computing adoption among students in Mangalore city, structured questionnaires with multiple choices were implemented through Google Forms. The questionnaires were targeted to the students. Overall, 92 respondents participated in the survey.

\section{Research Objective 1: Gender of the participated} subjects
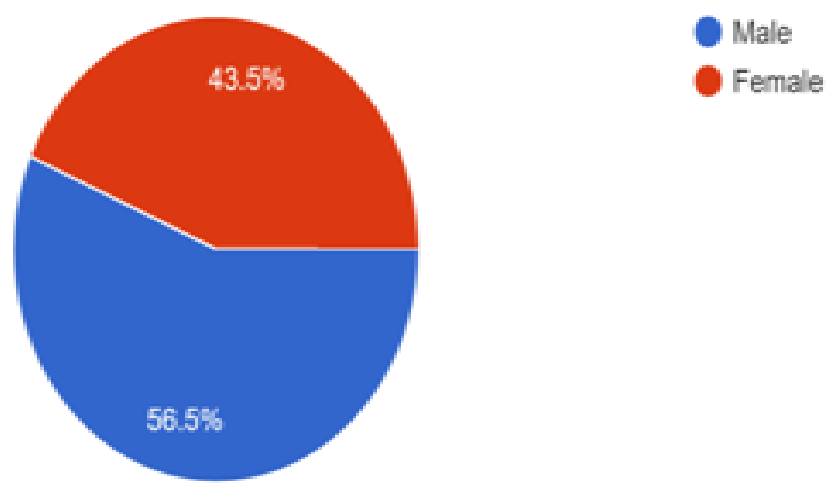

The answers to this question depicts that $56.5 \%$ of respondents among 92 responses received for this question, were males and $43.5 \%$ of respondents were females.
Research Objective 2: Age group of the participants

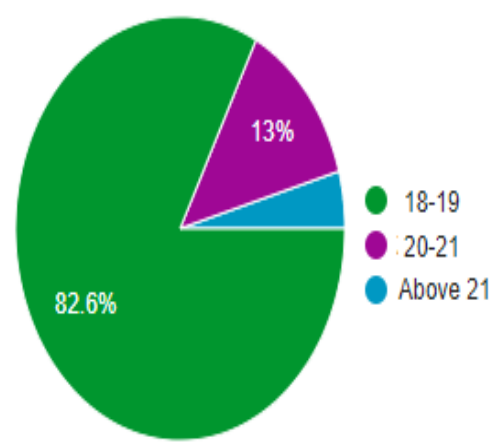

Majority of the respondents are in the age group 1819 Research objective 3: Do you know cloud
Computing?

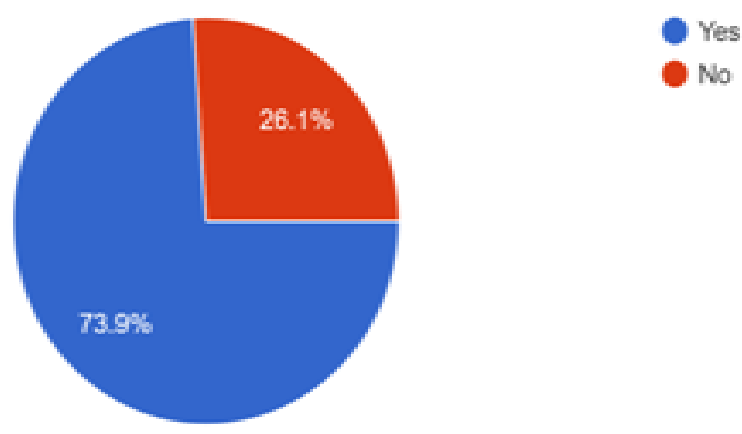

To investigate the perception of students who support cloud computing. In order to achieve this goal, a number of questions were projected and the survey revealed that $73.9 \%$ of respondents among 92 responses knew about "Cloud Computing" utilities or services and $26.1 \%$ of respondents did not know about cloud computing.

Research objective 4: Are you using Cloud Computing? 


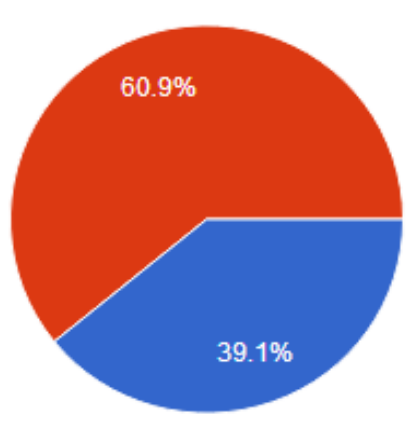

To know the extent of cloud computing adoption among students in Mangalore city. The answers to this question depicts that $39.1 \%$ of respondents among 92 responses received for this question, were using "Cloud Computing" utilities or services and $60.9 \%$ of respondents were not using cloud computing technology or services. The level of cloud adoption among degree students in Mangalore is perceived to be low..

\section{Research objective 5: Do you know how it works?}

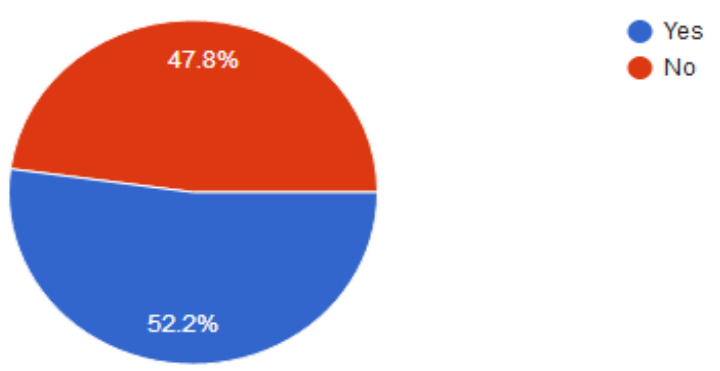

The answers to this question depicts that $52.2 \%$ of respondents among 92 responses received for this question, were aware of the working of "Cloud Computing" utilities or services and $47.8 \%$ of respondents were not aware of the working of cloud computing technology or services.
Research objective 6: How do you rate your knowledge on "Cloud Computing"?

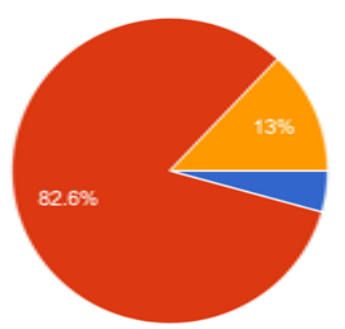

Knowledgeable - Some What Knowledgeable Not at all knowledgeable

Among 92 answers received for this question, 82.6\% of respondents were "somewhat knowledgeable" while $13 \%$ of the respondents did not have knowledge and the rest $4.3 \%$ respondents had knowledge on cloud computing indicating the utmost necessity for training and advertising this concept more in order to encourage students to use its utilities and services in order to make best use of this technology for their education and have their skills updated with advancements.

\section{Research objective 7: How much do you trust using "Cloud Computing"?}

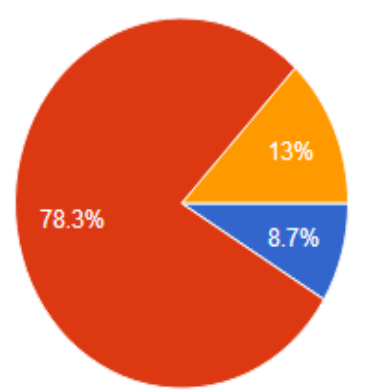

Fully Trust

Trust

Donot trus

The data obtained from the survey shows that $8.7 \%$ of respondents fully trusted cloud computing, 78.3\% of other respondents just trusted cloud computing and only $13 \%$ of respondents have no trust on it. 
Research objective 8: Cloud computing is less time consuming than traditional uses of computer and internet for learning.

$73.9 \%$ of the respondents agree that cloud computing is less time consuming than traditional uses of computer and internet for learning.
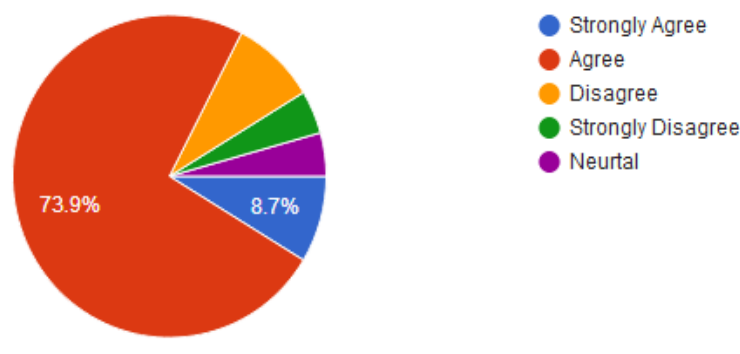

Research objective 9: Are you willing to use the cloud for education purposes?

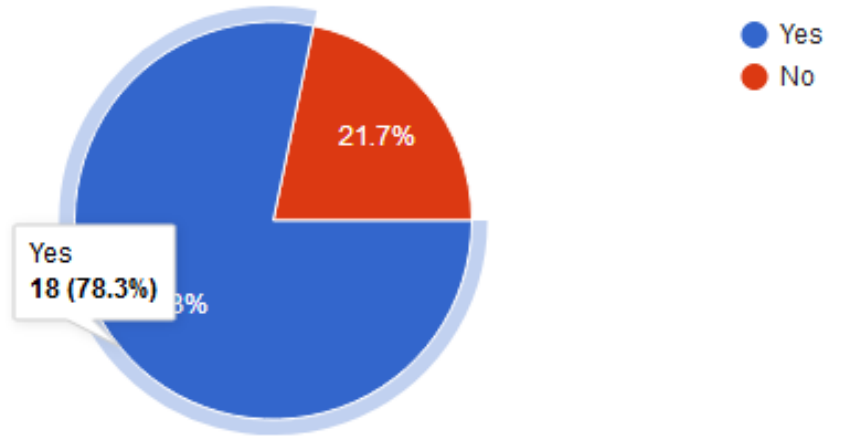

$78.3 \%$ of respondents were willing to adopt cloud computing in education.

Research objective 10: According to you, what are the factors that affect the adoption of cloud computing in education?

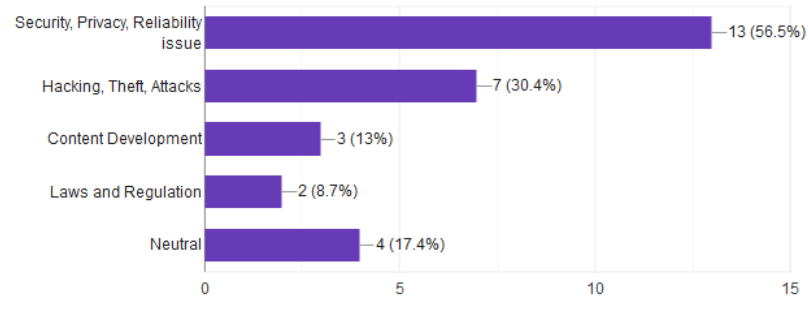

The factors that affect the adoption of cloud computing are: Security, Privacy, Reliability issue as
$56.5 \%$ of the respondents think that these are the major factors that prevents students from adoption of Cloud Computing technology. Hacking, Theft, Attacks $-30.4 \%$, Content Development- 13\%, Laws and Regulation $-8.7 \%$ and Neutral-17.4\% of respondents remain neutral in their opinion.

\section{SOLUTION}

As the advancement in cloud computing, students must take proactive measures to ensure security by the data encryption. The user community needs to send and store minimal personal information in the cloud. Cloud Service Provider should enable and make best use of the user control and provide feedback.

Research objective 11: Do you need awareness regarding the usage of cloud?

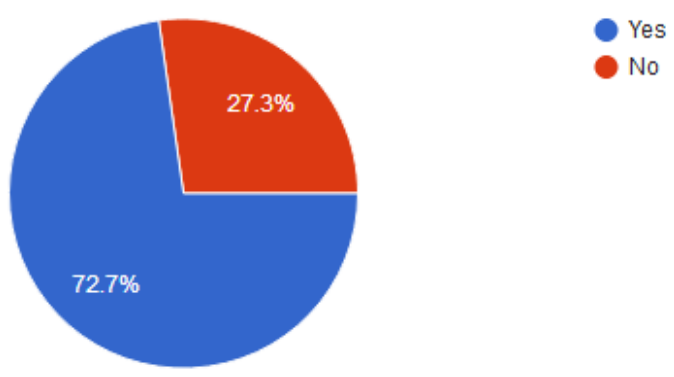

The response received depicts that $72.7 \%$ of respondents among 92 responses received for this question, needed awareness on "Cloud Computing" utilities or services.

Research objective 12: Do you think cloud computing will help you in your academics?

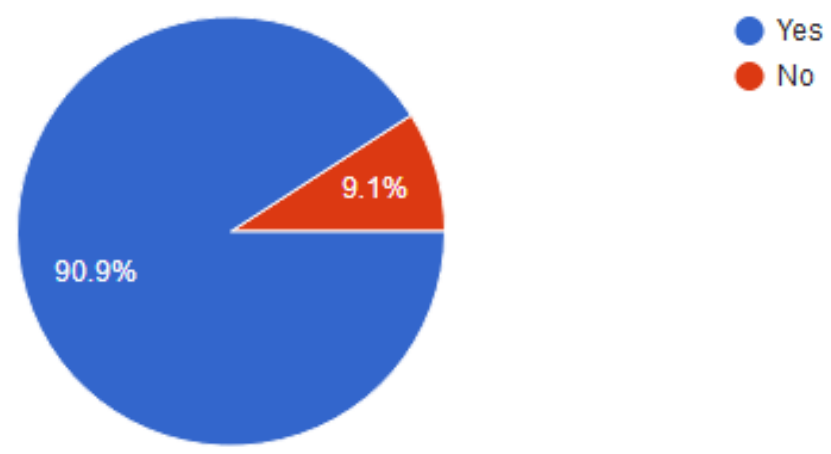

The response received depicts that $90.9 \%$ of respondents among 92 responses think that cloud computing will help them in academics. 


\section{DISCUSSION}

This research seeks to evaluate the factors affecting the adoption of cloud computing among the students. This was achieved quantitatively with the use of Google forms. The findings of this research approach are discussed based on the research findings through the survey and the literature reviewed. Inspite cloud computing technology is evolving internet based technology that can be easily accessible, the E-skills and the updated knowledge on its utilization is of utmost importance, only then can its adoption can be user friendly. And also one needs to be aware of the challenges or the risks of using this technology, hence the secure data storage and also data access in cloud is a pre-requisite. Individual needs to send and store minimal personal information in the cloud to be on the safe zone. It is the need of the hour to create awareness and provide training in order to use the cloud computing technology in education by the students so they can the best usage in their career growth.

\section{Limitations of the survey}

The sample chosen has an inherent limitation for this survey as it was restrained to the students from single university and 53.8\% respondents were majorly from the same college inspite subjects participated from different combination of degree courses from this University. Therefore, the future research should also target multiple colleges and universities and additionally, should also consider expanding demographics to include users in various countries. In addition, a future study could investigate in more detail which features of cloud computing helps increase students' effectiveness and efficiency in the classroom.

\section{RECOMMENDATION AND CONCLUSION}

The following are the core finding of the research. $73.9 \%$ of the students are totally aware of cloud computing technologies. $78.3 \%$ of the students think that cloud computing will play major role in education in the organization for collaboration and are willing to adopt cloud computing. Major factors such as Security, Privacy, Reliability issues makes $56.5 \%$ of the responding students believe that cloud is somewhat insecure preventing students from adoption of Cloud computing technology. Although many students tend to trust the services rendered by the cloud, not all students feel secure to store confidential data on someone else's storage. Storage and accessibility of cloud data is possible from the remote servers through the applications via internet and has its own challenges or risks. Therefore, security challenges are to be taken care by the organization while catering to the needs of the education and administration when implementing cloud computing technology.

The cloud computing is a rapidly developing Internet-based computing model. Combination of elearning using cloud computing in education opens up new ideas for further development. Cloud Computing technology is an attractive economic option to the Institution. The learning process could be favoured by the adoption of cloud computing in IT operations which aids educational system. The data security is the biggest challenges facing the Institution to adopt any new technology. The Cloud Computing helps to reduce the expenses that go to buy hardware, servers, software or maintenance. There are free services in the cloud help students to communicate with each other, save and share data and others. The paper highlights the usage of cloud is not adequate in the degree level colleges, which needs to be improved. In-order to increase competiveness of students in the job market, it is the 
responsibility of educational institutions and the government to ensure that their students are equipped with knowledge of this highly demanded technology. Cloud computing serves to the easy accessibility, cost effectiveness in the field of education and can promote quality education for overcoming the digital divide among the less opportunistic and in the rural areas.

To use cloud computing by the students in favour of their education requires appropriate training and user friendly approach to gain interests when imposed by the teachers. Additionally, the facilities and financial aid is a pre-requisite from the organizations and the Government to potentially adopt the evolving internet based cloud computing technology.

Cloud computing is promising in the improvement of rural education through digital literacy, aiding in quality education when the students gain e-skills and utilise the freely available data and applications in creating and developing new projects with updated information thereby enriching their knowledge. In order to enhance this E-learning through cloud services in rural areas right guidance to the educational institutes needs to be provided and made accessible to them. Cloud based education in rural areas will be beneficial in providing quality education with updated learning resources of reduced cost, fast accessible free data and applications and mainly the Universities could take in-charge of the data encryption with security and its maintainence with trained officials.

In conclusion, through our survey we explored that creating awareness, literacy and training the students and teachers on cloud based education in rural areas and Universities with the government aid is of utmost importance for the fast progress through Elearning. For promoting digital literacy, National Digital Literacy Mission and Digital Saksharta
Abhiyan are the Government approved schemes wherein the digital devices like computers, tablet PCs, smartphones and Internet can be used. For the effective digital literacy, cloud computing needs to be used by the policy makers.

\section{REFERENCES}

[1]. Factor Analysis of the Adoption of Cloud Computing In Nigeria R.K. Awosan (Member, IEEE) Department of Information Technology Sikkim Manipal University Indian 5th Mile, Tadong, Gangtok -737 102, India

[2]. AIMA Journal of Management \& Research, May 2016, Volume 10 Issue 2/4, ISSN 0974 - 497 Copy

[3]. Kostanica, Fitore \& Youssef, Adel \& Zeqiri, Adelina. (2017). Factors affecting intention to adopt cloud computing by students in kosovo.

[4]. Salunkhe, U., \& Kelkar, S. (2016). A Study on the Scope of Cloud Computing in Management Education.

[5]. Zeqiri, A., Aliu, L., Kostanica, F., \& Prenaj, B. (2017). An empirical investigation of cloud computing usage in education. La Revue des Sciences de Gestion, (3), 77-85.

[6]. Chinyao Low, Yahsueh Chen, Mingchang $\mathrm{Wu}$, (2011) "Understanding the determinants of cloud computing adoption", Industrial Management \& Data Systems, Vol. 111 Issue: 7, pp.1006-1023, https://doi.org/10.1108/02635571111161262

\section{Cite this article as :}

Mrs. Sowmya Jyothi , "Survey on examining the student's cognizance on usage of Cloud Computing in Higher Education", International Journal of Scientific Research in Computer Science, Engineering and Information Technology (IJSRCSEIT), ISSN : 2456-3307, Volume 7 Issue 2, pp. 348-354, March-April 2021. Available at doi $\quad$ : https://doi.org/10.32628/CSEIT217226

Journal URL : https://ijsrcseit.com/CSEIT217226 